\title{
Application of spaceborne synthetic aperture radar data for extraction of soil moisture and its use in hydrological modelling at Gottleuba Catchment, Saxony, Germany
}

\begin{abstract}
Hydrological modelling is a powerful tool for hydrologists and engineers involved in the planning and management of water resources. With the recent advent of computational power and the growing availability of spatial data, remote sensing and geographical information systems technologies can augment to a great extent the conventional methods used in rainfall run-off studies. That means it is possible to accurately describe the characteristics of watershed in particularly when determining the run-off response to rainfall inputs. The main objective of this study is to apply the potential application of spaceborne synthetic aperture radar (SAR) data (i.e. TerraSAR-X and Advanced Land Observing Satellite/Phased Array type L-band Synthetic Aperture Radar (ALOS PALSAR) for soil moisture retrieval) and to improve the spatial input parameters required for hydrological modelling. For the spatial database creation, a high-resolution 2-m aerial laser scanning digital terrain model, soil map, and land use map were used. Rainfall records were transformed into a run-off through hydrological parameterisation of the watershed using Hydrologic Engineering Center's Hydrologic Modelling System (HEC-HMS) software for rainfall run-off simulation. The Soil Conservation Services Curve Number and soil moisture accounting loss methods were selected to calculate the infiltration losses. In this research, soil moisture was derived from two different types of spaceborne SAR data: TerraSAR-X and ALOS PALSAR (L-band). The developed integrated hydrological model was applied to a flood prone area: Gottleuba Catchment in Pirna (Saxony, Germany). For model validation, 10 years historical precipitation data were used. The validated model was further optimised using the extracted soil moisture from SAR data. The simulation results showed a reasonable match between the simulated and the observed hydrographs. Hence, this paper confirms that TerraSAR-X and ALOS PALSAR (L-band) have a high potential for soil moisture mapping as a useful source of information and technique in hydrological modelling.
\end{abstract}

Keyword: Flood; Germany; GIS; HEC-HMS; Modelling; Remote sensing; TerraSAR-X; 